\title{
(2) OPEN ACCESS \\ Prehospital management of exertional heat stroke at sports competitions for Paralympic athletes
}

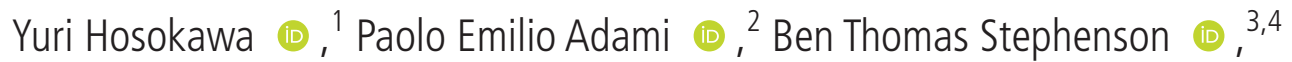 \\ Cheri Blauwet, ${ }^{5,6}$ Stephane Bermon, ${ }^{2,7}$ Nick Webborn, ${ }^{6,8}$ Sebastien Racinais (ㄷ) ${ }^{9}$ \\ Wayne Derman (1), 10,11 Victoria L Goosey-Tolfrey (1) ${ }^{3,12}$
}

For numbered affiliations see end of article.

Correspondence to Dr Paolo Emilio Adami, Health and Science, World Athletics, Monte Carlo, Monaco, Monaco; paoloemilio.adami@ worldathletics.org

Accepted 27 September 2021

\begin{abstract}
Objectives To adapt key components of exertional heat stroke (EHS) prehospital management proposed by the Intenational Olympic Committee Adverse Weather Impact Expert Working Group for the Olympic Games Tokyo 2020 so that it is applicable for the Paralympic athletes. Methods An expert working group representing members with research, clinical and lived sports experience from a Para sports perspective reviewed and revised the IOC consensus document of current best practice regarding the prehospital management of EHS.

Results Similar to Olympic competitions, Paralympic competitions are also scheduled under high environmental heat stress; thus, policies and procedures for EHS prehospital management should also be established and followed. For Olympic athletes, the basic principles of EHS prehospital care are: early recognition, early diagnosis, rapid, on-site cooling and advanced clinical care. Although these principles also apply for Paralympic athletes, slight differences related to athlete physiology (eg, autonomic dysfunction) and mechanisms for hands-on management (eg, transferring the collapsed athlete or techniques for whole-body cooling) may require adaptation for care of the Paralympic athlete. Conclusions Prehospital management of EHS in the Paralympic setting employs the same procedures as for Olympic athletes with some important alterations.
\end{abstract}

\section{INTRODUCTION}

With the increasing knowledge in the clinical management of heat-related illnesses, development of specific guidelines and protocols to treat exertional heat stroke (EHS) and other heat-related conditions are becoming readily available. ${ }^{1-3}$ These documents are of high relevance considering global warming, the increasing number of mass participation events that take place in extreme environments and the increasing number of participants of all competitive levels engaging in these events. Although elite athletes, including Paralympic athletes, are more likely to be better prepared for competing in the heat (ie, heat acclimatisation, precooling and par-cooling) the medical care provided in elite events follow the same principles as those applied at mass participation events. The environmental conditions at the Tokyo 2020 Summer Olympic and Paralympic Games have raised concerns among teams, organisers and the scientific community due to the expected high temperatures and relative humidity, based on the recent trends and reports. ${ }^{4}$ In this context, a new set of guidelines for prehospital management of EHS at the Tokyo 2020 Olympic Games was recently published, focusing on the medical care and logistical set up required to provide high-quality care at the sporting venue. ${ }^{3}$ Although the clinical management of EHS in athletes competing in Para sport may adopt the same principles, there are substantial differences that should be taken into consideration when organising prehospital management strategies.

Athletes at the Paralympic Games are classified into 10 impairment types (eight physical impairments as well as visual and intellectual impairments) resulting in a heterogeneous athlete population. The available evidence indicates that the incidence of EHS in the Paralympic athlete population is low. ${ }^{5-7}$ Nonetheless, some Paralympic athletes across the spectrum of eligible impairments are inherently at greater risk of thermoregulatory strain during exercise in the heat (table 1). As such, heat syncope/ exhaustion are still possible, and clinicians must be prepared to manage these athletes appropriately at the Paralympic Games and other events globally. Additionally, given the ever-increasing standard and professionalism of Paralympic sports (eg, 124 Paralympic records were broken during the Tokyo 2020 Paralympics) and the trend towards international events being staged in hot and/or humid environments and the increased prevalence of foreseen heatwaves, ${ }^{8}$ including the 2024 venue in Paris and 2028 venue in Los Angeles, the prevalence of EHS will likely increase over time.

\section{EHS PREHOSPITAL CARE OVERVIEW}

Basic components of EHS prehospital care include: (1) early recognition, (2) early diagnosis, (3) rapid, on-site cooling and (4) advanced clinical care. ${ }^{3}$ Unlike other sports-related medical emergency (eg, spinal injury, brain trauma, complex fracture), EHS requires the treatment to be completed on-site first, before the patient is transported to the advanced care. ${ }^{9}$ This is due to the fact that the duration of sustained hyperthermia is known to dictate patient prognosis. ${ }^{10}$ A delay in appropriate recognition, diagnosis and cooling can lead to catastrophic outcome. ${ }^{11} 12$ Current clinical best practice suggests that EHS patients must be cooled until their core body temperature is below $39^{\circ} \mathrm{C}$ within 30 min of the onset. ${ }^{3}$ Therefore, it becomes critical that medical providers working at sporting events with risk of EHS are well equipped with skills and resources to execute (1) rectal temperature assessment to confirm the diagnosis, (2) rapid cooling 
Table 1 Examples of medical condition specific to Paralympic athletes in relation to thermoregulation

\begin{tabular}{|c|c|c|c|}
\hline Diagnosis & Thermoregulation considerations for in-competition performance & Para sport & $\begin{array}{l}\text { Reporting of heat-related illness } \\
\text { symptoms }\end{array}$ \\
\hline Spinal cord-related disorders & $\begin{array}{l}\text { Impairments in skin blood flow and sweat responses below the } \\
\text { lesion level, }{ }^{2425} \text { reduced venous return, }{ }^{26} \text { and higher body fat will all } \\
\text { contribute to increased heat storage for a given workload. }{ }^{27} \\
\mathrm{~T}_{\mathrm{c}} \text { typically increases continuously throughout competition, as well } \\
\text { as passive heating }{ }^{28} \text { (without cooling aids), highlighting the level of } \\
\text { thermoregulatory disruption. }\end{array}$ & $\begin{array}{l}\text { Wheelchair Rugby } \\
\text { Para Athletics } \\
\text { Para Archery } \\
\text { Paratriathlon }\end{array}$ & $\begin{array}{l}\text { Heat-related disorientation }{ }^{29} \\
\text { Convulsion }^{5} \\
\text { Heat-related fatigue }^{22} \\
\text { Heat-related illness }^{30}\end{array}$ \\
\hline $\begin{array}{l}\text { Non-spinal cord-related } \\
\text { neurological disorders }\end{array}$ & $\begin{array}{l}\text { Greater metabolic heat production of locomotion, for a given } \\
\text { workload, when compared with Olympic athletes. }{ }^{31} \\
\text { High muscular tone impairs venous return, increasing the } \\
\text { cardiovascular strain and relative intensity of exercise. }{ }^{32} \\
\text { Impaired pace awareness may increase their risk of thermoregulatory } \\
\text { strain. }{ }^{33} \\
\text { Increases in body and/or environmental temperature (without cooling) } \\
\text { can exacerbate neurological symptoms, including fatigue, in those } \\
\text { with multiple sclerosis, }{ }^{34} \text { where the sudomotor response to heating is } \\
\text { already impaired. }{ }^{35}\end{array}$ & $\begin{array}{l}\text { Para Athletics } \\
\text { Paratriathlon }\end{array}$ & $\begin{array}{l}\text { Heat exhaustion }^{5} \\
\text { Heat-related illness }{ }^{5} \\
\text { Heat-related illness }\end{array}$ \\
\hline Limb deficiency & $\begin{array}{l}\text { Display limited body surface area for evaporative and convective heat } \\
\text { loss, increasing heat storage. } \\
\text { Closer coupling of } \mathrm{T}_{c} \text { and } \mathrm{T}_{\mathrm{ss}} \text { which is further exacerbated by socket } \\
\text { liners and prostheses limiting heat dissipation. }{ }^{37} \\
\text { Skin grafts remove a portion of the skin capable of sweating } \\
\text { and cutaneous vasodilation, augmenting the impairment in } \\
\text { thermoregulatory capacity. }{ }^{38} \\
\text { Significant gait asymmetries, elevating metabolic heat production for a } \\
\text { given workload. }{ }^{39}\end{array}$ & $\begin{array}{l}\text { Para Athletics } \\
\text { Paratriathlon }\end{array}$ & $\begin{array}{l}\text { Cramps and collapse } \\
\text { Heat exhaustion } \\
\text { Heat-related illness } \\
\text { Heat-related illness }^{30}\end{array}$ \\
\hline Visual impairment & $\begin{array}{l}\text { Impaired pace awareness (depending on level of visual feedback) may } \\
\text { increase their risk of thermoregulatory strain. }{ }^{40} \\
\text { Difficulties in self-monitoring hydration through urine colour or volume } \\
\text { may cause issues during competition. }{ }^{41} \\
\text { Athletes with albinism are prone to sunburn in situations of } \\
\text { high radiant load. This exacerbates thermal sensation and limits } \\
\text { thermoregulation during exercise through a locally mediated effect on } \\
\text { sweat gland responsiveness and capacity. }{ }^{42}\end{array}$ & $\begin{array}{l}\text { Para Athletics } \\
\text { Paratriathlon }\end{array}$ & $\begin{array}{l}\text { Dermatological burn } \\
\text { Heat exhaustion } \\
\text { Heat-related illness } \\
\text { Heat-related illness }^{30}\end{array}$ \\
\hline
\end{tabular}

\footnotetext{
Grobler et $a l^{5}$ competitive athletics taking place in wet-globe temperatures $24.6-36.0^{\circ} \mathrm{C}$; Griggs et al ${ }^{29}$ wheelchair rugby match play at $18.4-20.9^{\circ} \mathrm{C}$ and $31.1 \%-45.1 \%$ relative humidity; Handrakis et a ${ }^{22}$ competitive archery outdoors for 10 hours (conditions not reported); Stephenson et a $\beta^{30}$ competitive paratriathlon in $33^{\circ} \mathrm{C}$ relative humidity $35 \%-$ $41 \%$. The reader is guided to Westaway et $a^{43}$ for lists of medications that can interfere with thermoregulation, dehydration and heat-related illness. Adapted from Stephenson and Goosey-Tolfrey ${ }^{44}$ and evidence of heat-related illness reported in Paralympic sports. ${ }^{316-18}$

$T_{c^{\prime}}$ body core temperature; $T_{s^{\prime}}$ skin temperature.
}

using whole-body cold-water immersion and (3) follow-up examination to assess discharge readiness.

When possible, it may be of benefit to acquire the athlete's medical history and ongoing therapy prior to the event since impairment type indicated by the competition class does not necessarily represent whether the athlete is predisposed to increase thermoregulatory strain. For example, eligibility in the Quad class of wheelchair tennis is not restricted to athletes with tetraplegia. Consequently, a player with a spinal cord injury at the C8 level or above versus a player with an upper limb myopathy will both be eligible, but the former is at higher risk for exertional heat illness. If personal medical information cannot be acquired due to medical privacy reasons, organisers of the event are advised to request participating athletes and staff to report any foreseeable heat-related issues prior to the day of the competition. Some of the key questions to ask include: (1) presence of thermoregulatory impairment and the reason, (2) history of exertional heat illness, (3) baseline blood pressure, if lower than the reference value and (4) any intake of medication that may alter the interpretation of vital signs.

\section{HEAT DECK/MEDICAL TENT}

Heat deck set-up and transfer of patient from field of play to medical tent

Heat deck, a designated area for EHS treatment and management, should be located within or adjacent to the main athlete medical tent. When the sport of interest involves Paralympic athletes, who compete in wheelchair sports (eg, wheelchair racing), the space within and corridor to the medical tent must be designed to accommodate the width of varying sports wheelchairs. Securing a clean water source, ice and appropriate drainage is at high priority to manage cold water immersion tubs.

Once the Paralympic athlete is suspected of experiencing EHS at the field of play, the athlete should be transferred directly to heat deck. Medical personnel assigned to work at Paralympic events should be familiar with transfer techniques of athletes with different impairments, particularly the collapsed athlete. Manual lifting in healthcare training programmes and policies are encouraged to prevent musculoskeletal injuries to the volunteers by athlete handling. ${ }^{13} 14$ If the Paralympic athlete collapses while in sports equipment (eg, sports wheelchair, handcycle), 


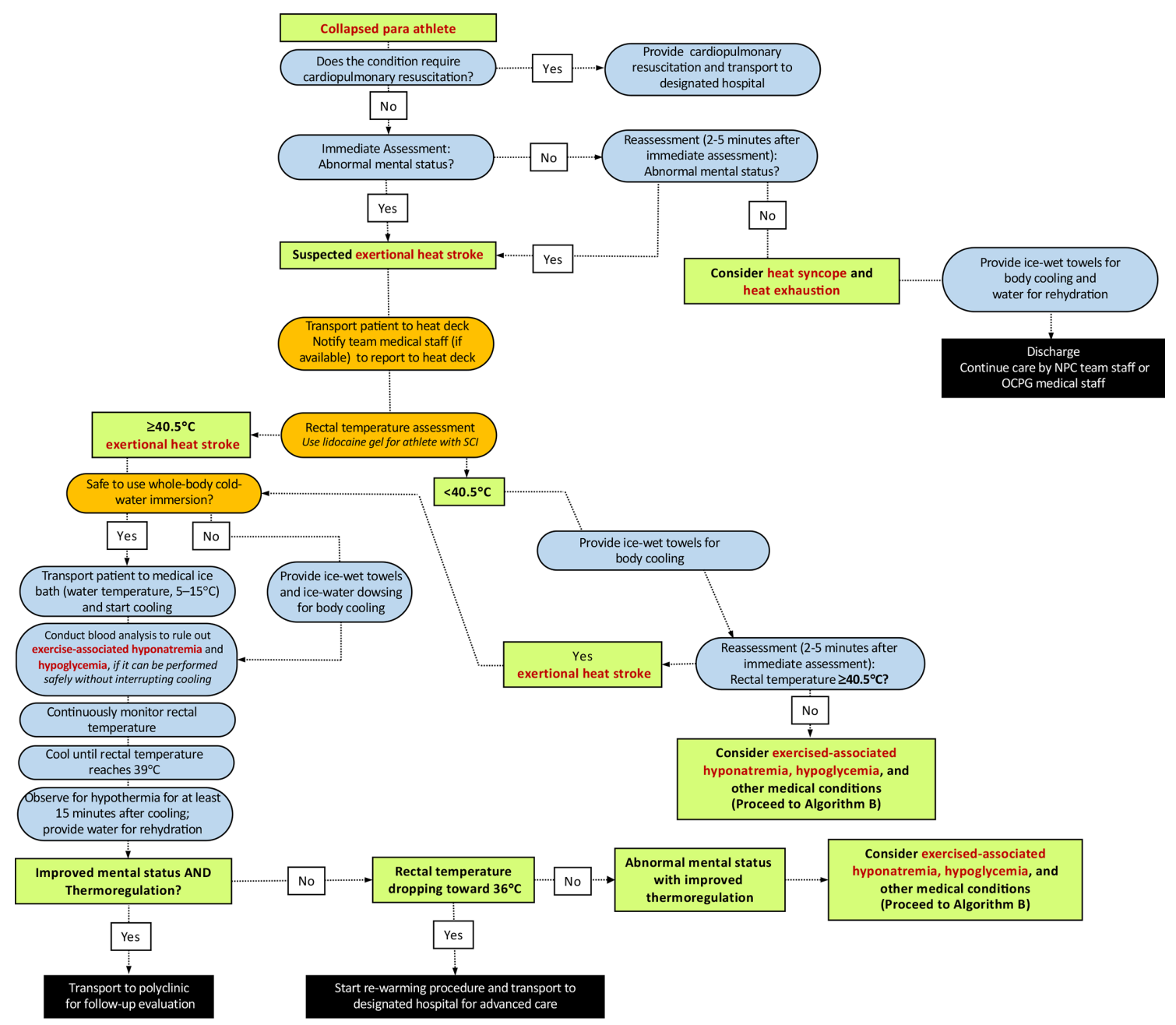

Figure 1 Algorithm (A1) for the initial diagnosis and management of a Paralympic athlete with suspected exertional heat stroke who has no risk of autonomic dysreflexia. NPC, National Paralympic Committee; OCPG, Organising Committees for the Paralympic Games; SCl, spinal cord injury.

carefully extricate the athlete from their equipment. Therefore, prior familiarisation with equipment and strapping used by athletes is important.

\section{Management of medical tent traffic}

Given the complexity of managing emergency medical conditions in Paralympic athletes, it is important that a team representative who knows the athlete well is allowed to enter the heat deck during EHS management. This will allow the team representative to provide impairment-specific information (including medications and therapeutic use exemption considerations) to the management team, which may assist in the selection of prehospital care procedures. For athletes with visual impairment, their guide should have a guaranteed entry to the medical tent to provide assistance in the care of the athlete. Furthermore, athletes with communication disability (eg, dysarthria) should be allowed to have their team representative accompany the athlete to facilitate communication throughout treatment, and to ensure that the athlete has returned to baseline mental status prior to discharge.

\section{PATIENT ASSESSMENT}

The general principles of prehospital EHS management in Paralympic athletes do not differ greatly from the standard care used in the general athletic context (figure 1). We encourage readers to review the paper by Hosokawa et al for an overview of the fundamental concepts. ${ }^{3}$

Rectal temperature should be assessed using a flexible probe to identify the extent of exercise-induced hyperthermia. If the collapsed athlete's impairment is in the category of spinal cord injury at or above T6, heart rate and blood pressure should be checked immediately, and then monitored for signs of autonomic dysreflexia (AD) (table 2). These athletes are also at higher risk for impaired thermoregulation (eg, overheating/EHS or overshoot during cooling). When assessing the rectal temperature of athletes with spinal cord injury at or above T6, lidocaine gel should be used to prevent the risk of $\mathrm{AD}$. However, such risk is minimal given this task constitutes only a brief, transient noxious stimulus. In relation to $\mathrm{AD}$, medical providers should also consider bowel and bladder distension as the cause of AD (as EHS is unlikely to be the direct cause of AD). The induction of $\mathrm{AD}$ can have major implications on heart rate and blood pressure (elevations) leading to a dangerous condition. The reader is guided to Blauwet et $a l^{15}$ for further guidance.

Before moving the athlete to whole-body cold-water immersion tub, assessment for pressure sores, open wounds and local burns should also be conducted thoroughly, which may be more prevalent in amputee athletes and athletes with insensate regions (paraplegia and tetraplegia). If open wounds are present, cover the area with an appropriately disinfected or new cold-water 
Table 2 Overview of the 22 sporting events at Tokyo Paralympic Games and the sports/events where athletes are at risk for autonomic dysreflexia (AD) and impaired thermoregulation with a spinal cord injury at or above the level T6

\begin{tabular}{lllll}
\hline Sports & $\begin{array}{l}\text { Spinal } \\
\text { cord-related } \\
\text { disorders }\end{array}$ & $\begin{array}{l}\text { Above } \\
\text { or at SCl } \\
\text { level T6 }\end{array}$ & $\begin{array}{l}\text { Environmental } \\
\text { heat stress }\end{array}$ & Event and class \\
\hline Archery & $\square$ & $\square$ & Moderate & W1 \\
Athletics & $\square$ & $\square$ & High & $\begin{array}{l}\text { WR track T51- } \\
\text { T53 }\end{array}$ \\
& & & & $\begin{array}{l}\text { Seated throws } \\
\text { F51-F53 }\end{array}$ \\
Badminton & $\square$ & $\square$ & Low & WH1 \\
Boccia & $\square$ & $\square$ & Low & BC1 \\
Canoe & $\square$ & $\square$ & Low & Kayak KL1 \\
Cycling & $\square$ & $\square$ & High & Handcycling H1 \\
Equestrian & $\square$ & $\square$ & Moderate & - \\
\hline $\begin{array}{l}\text { Football (5-a- } \\
\text { side) }\end{array}$ & $\square$ & $\square$ & Moderate & - \\
\hline
\end{tabular}

\begin{tabular}{|c|c|c|c|c|}
\hline Goalball & $\square$ & ૧ & Low & - \\
\hline Judo & $\square$ & $\square$ & Low & - \\
\hline Powerlifting & $\nabla$ & $\square$ & Low & - \\
\hline Rowing & $\nabla$ & $\nabla$ & Moderate & AS \\
\hline Shooting & $\nabla$ & $\nabla$ & Moderate & Rifle SH2 \\
\hline Sitting volleyball & $\square$ & $\nabla$ & Low & - \\
\hline Swimming & $\nabla$ & $\nabla$ & Low & $\begin{array}{l}\text { S1 SB1 and S2 } \\
\text { SB1 }\end{array}$ \\
\hline Table tennis & $\nabla$ & $\nabla$ & Low & Class 1 \\
\hline Taekwondo & $\square$ & $\square$ & Low & - \\
\hline Triathlon & $\nabla$ & $\nabla$ & High & PTWC \\
\hline $\begin{array}{l}\text { Wheelchair } \\
\text { basketball }\end{array}$ & $\square$ & $\square$ & Moderate & - \\
\hline $\begin{array}{l}\text { Wheelchair } \\
\text { fencing }\end{array}$ & $\nabla$ & $\square$ & Low & - \\
\hline $\begin{array}{l}\text { Wheelchair } \\
\text { rugby }\end{array}$ & $\nabla$ & $\nabla$ & High & $\begin{array}{l}\text { Typically, } 0.5 \\
\text { and } 1.0\end{array}$ \\
\hline $\begin{array}{l}\text { Wheelchair } \\
\text { tennis }\end{array}$ & $\nabla$ & $\nabla$ & High & Quad class \\
\hline
\end{tabular}

Environmental heat stress taken from Griggs et al. ${ }^{6}$ For further guidance on $A D$ please refer to the work of Blauwet et al. ${ }^{15}$

$\mathrm{F}$, field; $\mathrm{SCl}$, spinal cord injury; T, track; WR, wheelchair racing.

immersion tub to avoid the risk of contamination. It should be noted that these steps must be taken expeditiously to avoid unnecessary delays in care.

\section{WHOLE BODY COLD-WATER IMMERSION}

Medical providers must continuously monitor rectal temperature throughout the cooling process to determine the end point of treatment (ie, rectal temperature reaches $39.0^{\circ} \mathrm{C}$ ) (figures 1-3). Clinicians should be reminded that inserting a rectal thermometer with proper technique (ie, use of lidocaine gel) is unlikely to cause $\mathrm{AD}$. The immersion tub size should be selected accordingly to the average body size of the participants. An immersion tub that is traditionally used for the purpose of recovery ice bath may not be suitable for EHS treatment as it may be too deep for medical providers to transfer the collapsed athlete in and out from the bath and has the risk of drowning (readers are referred to Hosokawa et al for sample size of the immersion tub). ${ }^{3}$ The use of a pole-less stretcher to transfer the Paralympic athlete in and out of the tub may have increased importance than Olympic athletes since manual handling and moving patients who have mobility limitations requires some practice.
If an athlete with amputation experiences EHS and needs to be cooled, the prosthesis should be removed prior to immersion (or whenever possible, if it can be done safely) to maximise the skin surface to be cooled. In some cases, there will be a connection or interface device (commonly made of silicone), which should be removed to maximise the skin surface area to be cooled. In rare circumstances, where it is not safe to employ whole-body coldwater immersion (ie, athletes with known intellectual impairments who are not compliant to treatment measures), medical providers may choose whole-body rotating ice towels and/or ice water dousing as an alternative option, as these cooling methods have been shown to have adequate cooling rates. ${ }^{16}$ Tarp-assisted cooling (TACo) is another alternative cooling technique used to treat EHS. ${ }^{17}$ However, in the case where whole-body cold-water immersion is deemed unsafe, it is unlikely that the TACo method can be administered safely since it also involves significant patient transfer. Among a small group of Paralympic athletes at risk of $\mathrm{AD}$ (ie, spinal cord injury at or above T6), transfer and change in the positioning of the patient should be minimised as much as possible to prevent noxious inputs that could trigger AD. In such situations, medical providers may consider using a mix of wholebody rotating ice towels and partial body immersion (ie, entire upper extremity) (figure 2). The reader is directed to the work of Griggs $e a l^{18}$ and Pritchett $e t a l^{19}$ for more practical guidance. It should be emphasised that reduction of internal body temperature within the initial $30 \mathrm{~min}$ of collapse ensures survival and minimises the severity of sequela. ${ }^{20}$

Finally, a laboratory study suggests that the risk of hypothermic overshoot may be more pronounced among athletes with impaired thermoregulation (eg, athletes with a spinal cord injury). ${ }^{21}$ Medical providers should monitor the rate of cooling closely as it may be faster compared with athletes with no disability. ${ }^{22} 23$

\section{Hygiene-related considerations}

Consider stump hygiene and skin health of athletes with a limb deficiency, particularly of the lower limb. While the residual limb may display skin irritation, if whole-body cold-water immersion is the preferred option, then ensure that once the prosthesis is removed, the area is fully dried post-immersion and cleansed to prevent infection.

Athletes with colostomy bags should still be cooled using whole-body cold-water immersion to prioritise life-saving procedure; however, whole-body cold-water immersion tub used to cool athletes with colostomy bag should be drained and disinfected after each use. If available, consider designating a large shower room (ie, such as those seen in sports arenas and locker rooms) where running water can be used to also cleanse the athlete while protecting privacy.

\section{POST-TREATMENT}

There are currently no Para-athlete specific considerations for post-EHS treatment follow-up in the athlete medical tent. It is recommended that the need for specific testing be left to the team physician rather than medical tent team due to the wide variety of medical complications in Paralympic athletes.

\section{CONCLUSION}

Prehospital management of EHS in the Paralympic setting employs the same procedures as for an Olympic athlete with some important alterations. These include additional preparations to assist transport of Para-athletes with mobility equipment, planning for alternative whole-body cooling methods if 


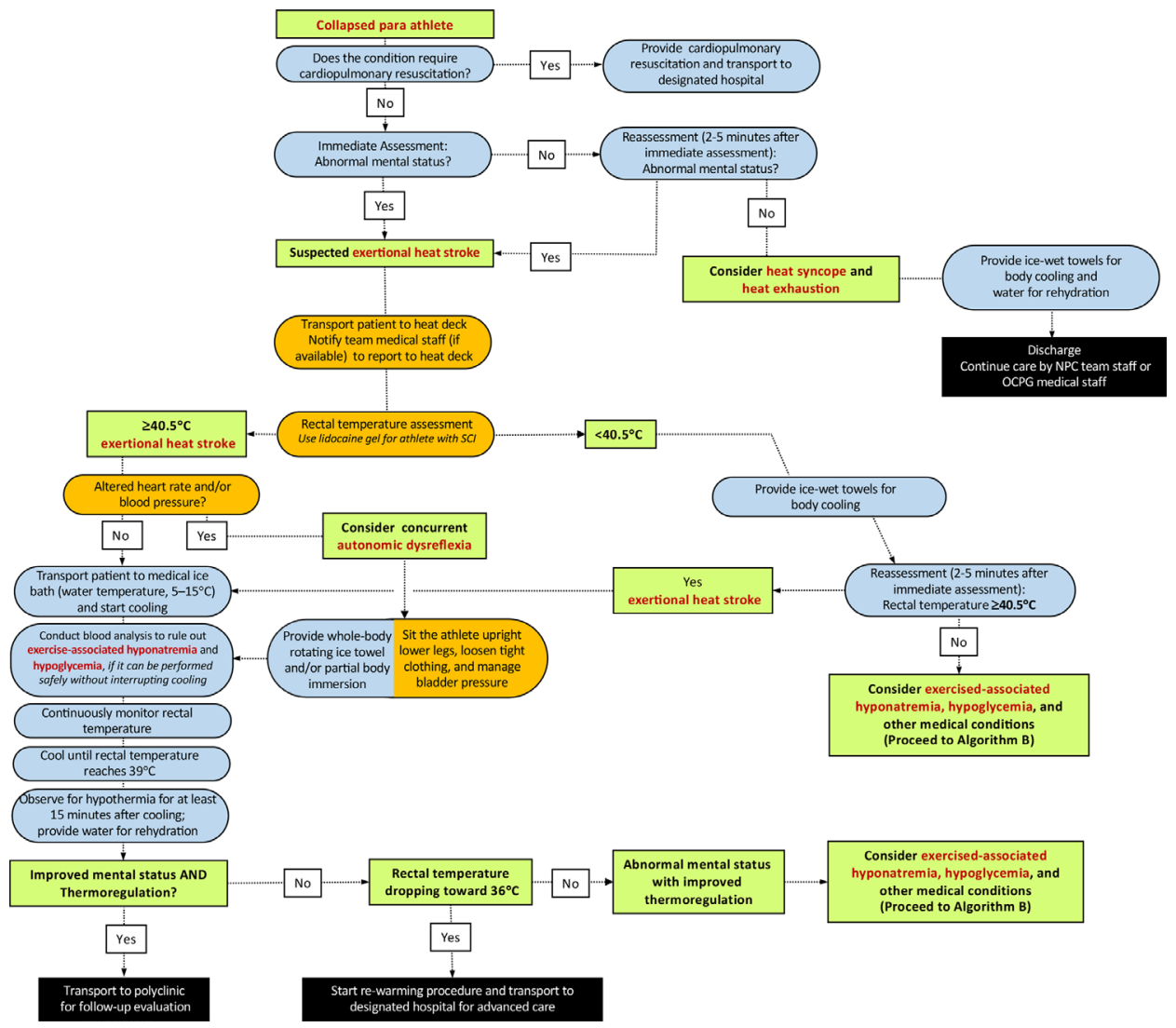

Figure 2 Algorithm (A2) for the initial diagnosis and management of a Paralympic athlete with suspected exertional heat stroke who has potential risk of autonomic dysreflexia and impaired thermoregulation (ie, individuals with spinal cord injury at T6 or above). NPC, National Paralympic Committee; OCPG, Organising Committees for the Paralympic Games; SCl, spinal cord injury.

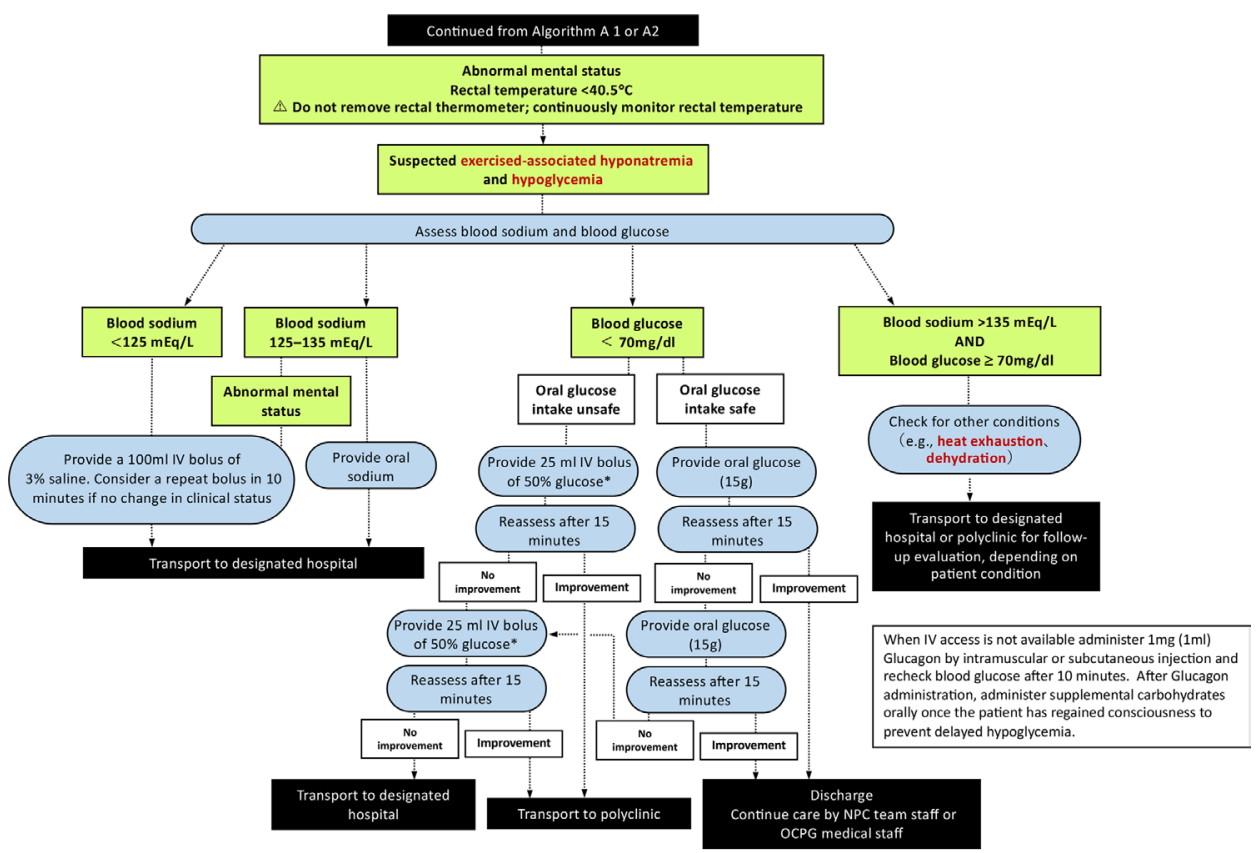

"Treating doctor must complete and submit a retroactive TUE for the patient

Figure 3 Algorithm (B) for the management of an athlete with exertional heat stroke (continued from figures 1 and 2). When intravenous access is not available administer $1 \mathrm{mg}(1 \mathrm{~mL})$ Glucagon by intramuscular or subcutaneous injection and recheck blood glucose after 10 min. After Glucagon administration, administer supplemental carbohydrates orally once the patient has regained consciousness to prevent delayed hypoglycaemic. NPC, National Paralympic Committee; OCPG, Organising Committees for the Paralympic Games. 
cold water immersion is deemed unsafe, and extra precautions and monitoring for athletes at risk of $\mathrm{AD}$. We hope that event and team medical practitioners and Para athletes themselves are familiar with the prehospital management of EHS, since global warming poses a significant risk to Para sport competitions in the future.

\section{What are the findings?}

- The incidence of exertional heat stroke (EHS) is relatively low among Paralympic athletes, but with increased global warming and interest to host world stage events in hot and humid environments the risk of EHS in Paralympic athletes may increase over time.

- Medical providers are advised to review participating athletes' impairment classification and categories prior to the event in order to apply impairment-specific considerations to safely treat Paralympic athletes with suspected EHS.

- Paralympic athletes with autonomic dysfunction may experience altered thermoregulation, putting them at higher risk of EHS, as well as hypothermic overshoot during cold water immersion.

- Athletes with significant mobility disability with suspected EHS may warrant whole-body cooling options other than cold water immersion to ensure safety and ease of care.

\section{How might it impact on clinical practice in the future?}

- While the core principles of prehospital management of EHS for Paralympic athletes are no different from the standard care used in the general athletic context, extra caution may be required regarding specific physiological differences (eg, autonomic dysfunction) that impact the management of the altered or collapsed athlete.

- Due to the heterogeneous athlete population, a thorough knowledge and awareness of the physiological and thermoregulatory responses in Paralympic athletes is required to optimise medical services at sporting events.

\section{Author affiliations}

${ }^{1}$ Faculty of Sport Sciences, Waseda University, Saitama, Japan

${ }^{2}$ Health and Science Department, World Athletics, Monaco

${ }^{3}$ Peter Harrison Centre for Disability Sport, School of Sport, Exercise and Health Sciences, Loughborough University, Loughborough, UK

${ }^{4}$ English Institute of Sport, Loughborough University, Loughborough, UK ${ }^{5}$ Department of Physical Medicine and Rehabilitation, Spaulding Rehabilitation; Spaulding Hospital/Brigham and Women's Hospital, Harvard Medical School, Boston, Massachusetts, USA

${ }^{6}$ Medical Committee, International Paralympic Committee, Bonn, Germany 7 LAHMESS, Universite Cote d'Azur, Nice, Provence-Alpes-Cote d'Azu, France ${ }^{8}$ Centre for Sport and Exercise Science and Medicine (SESAME), School of Sport and Service Management, University of Brighton, Brighton, UK

${ }^{9}$ Research Education Centre, ASPETAR - Qatar Orthopaedic and Sports Medicine Hospital, Doha, Qatar

${ }^{10}$ Institute of Sport and Exercise Medicine, Division of Orthopaedic Surgery, Department of Surgical Sciences, Faculty of Medicine and Health Sciences, Stellenbosch University, Stellenbosch, South Africa

${ }^{11}$ IOC Research Center, University of Stellenbosch, Cape Town, South Africa ${ }^{12}$ IOC Research Center, The National Centre for Sports Exercise and Medicine, Loughborough University, Loughborough, UK

Twitter Paolo Emilio Adami @paolo_emilio, Ben Thomas Stephenson @bstephenson311, NickWebborn @SportswiseUK, Sebastien Racinais @ephysiol and Wayne Derman @wderman

Acknowledgements The authors would like to thank Marco Bernardi, Sergio Migliorini, Yoshi Kamijo, Fumihiro Tajima, Michelle Trbovich for their expert opinion and support.
Contributors $Y H, P E A, S B$ and VLG-T contributed to the conception or design of the work. YH, PEA and VLG-T drafted the manuscript. YH, PEA, BTS, CB, SB, NW, SR, WD and VLG-T critically revised the manuscript. All gave final approval and agree to be accountable for all aspects of work ensuring integrity and accuracy.

Funding The authors have not declared a specific grant for this research from any funding agency in the public, commercial or not-for-profit sectors.

Competing interests WD reports grants from IOC Research Centers Grant, other from IPC Travel Support, grants from World Rugby, grants from AXA, grants from Ossur, outside the submitted work.

Patient and public involvement Patients and/or the public were not involved in the design, or conduct, or reporting, or dissemination plans of this research.

Patient consent for publication Not applicable.

Provenance and peer review Not commissioned; externally peer reviewed.

Data availability statement Data sharing not applicable as no datasets generated and/or analysed for this study.

Open access This is an open access article distributed in accordance with the Creative Commons Attribution Non Commercial (CC BY-NC 4.0) license, which permits others to distribute, remix, adapt, build upon this work non-commercially, and license their derivative works on different terms, provided the original work is properly cited, appropriate credit is given, any changes made indicated, and the use is non-commercial. See: http://creativecommons.org/licenses/by-nc/4.0/.

\section{ORCID iDs}

Yuri Hosokawa http://orcid.org/0000-0001-9138-5361

Paolo Emilio Adami http://orcid.org/0000-0001-5975-5342

Ben Thomas Stephenson http://orcid.org/0000-0003-4885-1974

Sebastien Racinais http://orcid.org/0000-0003-0348-4744

Wayne Derman http://orcid.org/0000-0002-8879-177X

Victoria L Goosey-Tolfrey http://orcid.org/0000-0001-7203-4144

\section{REFERENCES}

1 Belval LN, Casa DJ, Adams WM, et al. Consensus Statement- prehospital care of exertional heat stroke. Prehosp Emerg Care 2018;22:392-7.

2 Casa DJ, DeMartini JK, Bergeron MF, et al. National athletic trainers' association position statement: exertional heat illnesses. J Athl Train 2015;50:986-1000.

3 Hosokawa Y, Racinais S, Akama T. Prehospital management of exertional heat stroke at sports Competitions: international Olympic Committee adverse weather impact expert Working group for the Olympic Games Tokyo 2020. Br J Sports Med 2021. [Epub ahead of print: 22 Apr 2021].

4 Matzarakis A, Fröhlich D, Bermon S, et al. Quantifying thermal stress for sport Events-The case of the Olympic Games 2020 in Tokyo. Atmosphere 2018;9:479.

5 Grobler L, Derman W, Racinais S, et al. Illness at a para athletics track and field world championships under hot and humid ambient conditions. Pm R 2019;11:919-25.

6 Griggs KE, Stephenson BT, Price MJ, et al. Heat-Related issues and practical applications for Paralympic athletes at Tokyo 2020. Temperature 2020;7:37-57.

7 Zhang Y, Bishop PA. Risks of heat illness in athletes with spinal cord injury: current evidence and needs. Front Sports Act Living 2019;1:68.

8 Ouzeau G, Soubeyroux J-M, Schneider M, et al. Heat waves analysis over France in present and future climate: application of a new method on the EURO-CORDEX ensemble. Climate Services 2016:4:1-12.

9 Casa DJ, McDermott BP, Lee EC, et al. Cold water immersion: the gold standard for exertional heatstroke treatment. Exerc Sport Sci Rev 2007;35:141-9.

10 Epstein Y, Yanovich R. Heatstroke. N Engl J Med 2019:380:2449-59.

11 Grundstein A, Knox JA, Vanos J, et al. American football and fatal exertional heat stroke: a case study of Korey Stringer. Int J Biometeorol 2017:61:1471-80.

12 Stearns RL, Casa DJ, O'Connor FG, et al. A tale of two heat strokes: a comparative case study. Curr Sports Med Rep 2016;15:94-7.

13 Fadul RM, Brown LM, Powell-Cope G. Improving transfer task practices used with air travelers with mobility impairments: a systematic literature review. J Public Health Policy 2014;35:26-42.

14 Hallmark B, Mechan P, Shores L. Ergonomics: safe patient handling and mobility. Nurs Clin North Am 2015;50:153-66.

15 Blauwet CA, Benjamin-Laing H, Stomphorst J, et al. Testing for boosting at the Paralympic games: policies, results and future directions. Br J Sports Med 2013;47:832-7.

16 McDermott BP, Casa DJ, Ganio MS, et al. Acute whole-body cooling for exerciseinduced hyperthermia: a systematic review. J Ath/ Train 2009;44:84-93.

17 Hosokawa Y, Adams WM, Belval LN, et al. Tarp-Assisted cooling as a method of whole-body cooling in hyperthermic individuals. Ann Emerg Med 2017;69:347-52.

18 Griggs KE, Price MJ, Goosey-Tolfrey VL. Cooling athletes with a spinal cord injury. Sports Med 2015;45:9-21.

19 Pritchett K, Broad E, Scaramella J. Hydration and cooling strategies for Paralympic athletes : applied focus. Challenges athletes may face at the upcoming Tokyo Paralympics. Curr Nutr Rep 2020;9:137-46. 
20 Demartini JK, Casa DJ, Stearns R, et al. Effectiveness of cold water immersion in the treatment of exertional heat stroke at the Falmouth road race. Med Sci Sports Exerc $2015 ; 47: 240-5$.

21 van der Scheer JW, Kamijo Y-I, Leicht CA, et al. A comparison of static and dynamic cerebral autoregulation during mild whole-body cold stress in individuals with and without cervical spinal cord injury: a pilot study. Spinal Cord 2018;56:469-77.

22 Handrakis JP, Trbovich M, Hagen EM, et al. Thermodysregulation in persons with spinal cord injury: case series on use of the autonomic standards. Spinal Cord Ser Cases 2017;3:1-8

23 Cheshire WP. Thermoregulatory disorders and illness related to heat and cold stress. Auton Neurosci 2016;196:91-104.

24 Freund PR, Brengelmann GL, Rowell LB, et al. Attenuated skin blood flow response to hyperthermia in paraplegic men. J Appl Physiol Respir Environ Exerc Physiol 1984;56:1104-9.

25 Normell LA. Distribution of impaired cutaneous vasomotor and sudomotor function in paraplegic man. Scand J Clin Lab Invest Supp/ 1974;138:25-41.

26 Hopman MT, Oeseburg B, Binkhorst RA. Cardiovascular responses in paraplegic subjects during arm exercise. Eur J Appl Physiol Occup Physiol 1992;65:73-8.

27 Graham-Paulson T, Perret C, Goosey-Tolfrey V. Case study: dose response of caffeine on 20-km handcycling time trial performance in a paratriathlete. Int J Sport Nutr Exerc Metab 2018;28:274-8.

28 Griggs KE, Havenith G, Price MJ, et al. Evaporative heat loss insufficient to attain heat balance at rest in individuals with a spinal cord injury at high ambient temperature. $J$ App/ Physiol 2019;127:995-1004.

29 Griggs KE, Havenith G, Price MJ, et al. Thermoregulatory responses during competitive wheelchair rugby match play. Int J Sports Med 2017;38:177-83.

30 Stephenson BT, Hoekstra SP, Tolfrey K, et al. High thermoregulatory strain during competitive paratriathlon racing in the heat. Int J Sports Physiol Perform 2020;15:231-7.

31 Maltais D, Wilk B, Unnithan V, et al. Responses of children with cerebral palsy to treadmill walking exercise in the heat. Med Sci Sports Exerc 2004;36:1674-81.
32 Kloyiam S, Breen S, Jakeman P, et al. Soccer-specific endurance and running economy in soccer players with cerebral palsy. Adapt Phys Activ Q 2011;28:354-67.

33 Runciman P, Tucker R, Ferreira S, et al. Paralympic athletes with cerebral palsy display altered pacing strategies in distance-deceived shuttle running trials. Scand J Med Sci Sports 2016;26:1239-48.

34 Christogianni A, Bibb R, Davis SL, et al. Temperature sensitivity in multiple sclerosis: an overview of its impact on sensory and cognitive symptoms. Temperature 2018;5:208-23.

35 Allen DR, Huang MU, Morris NB, et al. Impaired thermoregulatory function during dynamic exercise in multiple sclerosis. Med Sci Sports Exerc 2019;51:395-404

36 Epstein Y, Shapiro Y, Brill S. Role of surface area-to-mass ratio and work efficiency in heat intolerance. J Appl Physiol Respir Environ Exerc Physiol 1983;54:831-6.

37 Klute GK, Rowe GI, Mamishev AV, et al. The thermal conductivity of prosthetic sockets and liners. Prosthet Orthot Int 2007;31:292-9.

38 Crandall CG, Davis SL. Cutaneous vascular and sudomotor responses in human skin grafts. J App/ Physio/ 2010;109:1524-30.

39 Mengelkoch LJ, Kahle JT, Highsmith MJ. Energy costs \& performance of transtibial amputees \& non-amputees during walking \& running. Int J Sports Med 2014;35:1223-8

40 Taylor JB, Santi G, Mellalieu SD. Freestyle race pacing strategies (400 m) of elite ablebodied swimmers and swimmers with disability at major international championships. J Sports Sci 2016;34:1913-20.

41 Webborn N, Van de Vliet P. Paralympic medicine. Lancet 2012;380:65-71.

42 Bothwell JE. Pigmented skin lesions in tyrosinase-positive oculocutaneous albinos: a study in black South Africans. Int J Dermatol 1997;36:831-6.

43 Westaway K, Frank 0, Husband A, et al. Medicines can affect thermoregulation and accentuate the risk of dehydration and heat-related illness during hot weather. J Clin Pharm Ther 2015;40:363-7.

44 Stephenson B, Goosey-Tolfrey VL. Physiological considerations for paratriathlon training and competition. In: Migliorini S, ed. Triathlon medicine. Cham: Springer International Publishing, 2020: 393-415. 